\title{
Analisis Pemodelan Substitusi Fluida pada Sumur
}

\author{
Nova Linzai, Firman Syaifuddin dan Amien Widodo \\ Teknik Geofisika, Fakultas Teknik Sipil dan Perencanaan, Institut Teknologi Sepuluh Nopember (ITS) \\ Jl. Arief Rahman Hakim, Surabaya 60111 Indonesia \\ e-mail: firman@geofisika.its.ac.id
}

\begin{abstract}
Abstrak-Penelitian yang bertujuan untuk menganalisa efek perubahan fluida pengisi pori terhadap sifat fisik batuan (impedansi batuan). Data sumur yang digunakan adalah $\log \mathrm{S}$ wave, $\mathbf{P}$-wave, densitas, saturasi air dan porositas. Pemodelan data sumur yang dilakukan adalah pemodelan substitusi fluida (100\% air, minyak dan gas) dengan menggunakan teori BiotGassman. Penelitian ini menunjukkan bahwa hasil dari substitusi fluida sangat mempengaruhi kecepatan gelombang $P$ dan densitas, sedangkan perubahan terhadap kecepatan gelombang $S$ tidak terlalu signifikan. Reservoir pada sumur merupakan gas sand sehingga nilai kecepatan gelombang $P$ pada batuan ketika disubstitusi gas lebih besar daripada minyak.
\end{abstract}

Kata Kunci-Fisik Batuan, Fluida, Pori, Substitusi Fluida.

\section{PENDAHULUAN}

A DANYA fluida dalam pori batuan akan mempengaruhi properti elastic batuan yang bergantung pada tipe dan kuantitas fluida pengisi pori. Data fisik batuan (rock physics) membantu dalam membuat analisis dan identifikasi fluida dan kuantifikasi di reservoir. Sehingga data- data fisik batuan tersebut dapat digunakan pada pemodelan substitusi fluida. Pemodelan ini berdasarkan persamaan Gassmann yang digunakan untuk mendeteksi fluida pori dan mengukur ketidakpastian dari data log densitas dan sonic (gelombang $\mathrm{P}$ dan gelombang S). Teori Gassmann menyediakan persamaan pada kasus sebenarnya (real) ketika geologi sangat berpengaruh terhadap nilai referensi porositas dan kecepatan yang relatif besar. [4]

Tujuan penelitian ini adalah untuk membuat model log baru ketika terisi fluida air, minyak dan gas dan menganalisa pengaruh substitusi fluida terhadap respon log pada sumur. Pemodelan pada sumur yang akan dilakukan adalah substitusi fluida atau Fluid Replacement Modeling (FRM) untuk melihat perubahan terhadap Gelombang P (Vp), Gelombang S (Vs) dan densitas $(\rho)$

\section{DASAR TEORI}

\section{A. Pemodelan Substitusi Fluida}

Pendekatan secara teori yang umum digunakan dalam substitusi fluida adalah Teori Gassmann [3]

$K s a t=K^{*}+\frac{\left(1-\frac{K^{*}}{K o}\right)^{2}}{\frac{\varnothing}{K f l}+\frac{(1-\varnothing)}{K o}-\frac{K^{*}}{K o^{2}}}$

Dimana:

$\mathrm{K}_{\mathrm{sat}} \quad$ : Bulk modulus batuan tersaturasi (undrained of pore fluids)
$\mathrm{K}_{\mathrm{o}} \quad$ : Bulk modulus matriks mineral

$\mathrm{K}_{\mathrm{fl}} \quad$ : Bulk modulus fluida pengisi pori

$\mathrm{K}^{*} \quad$ : Bulk modulus kerangkabatuan (drained on any porefilling fluid)

$\varnothing \quad$ : Porositas

Aplikasi persamaan Gassman dibangun berdasarkan asumsi sebagai berikut:

1. Model batuan diasumsikan homogen dan isotropis dan setiap pori terkoneksi

2. Persamaan Gassman hanya valid pada frekuensi cukup rendah sehingga tekanan dalam pori meyerupai skala panjang yang lebih dari dimensi pori dan kurang dari panjang gelombang seismic yang melewati.

Persamaan Gassmann terkadang tidak dapat digunakan dalam kondisi porositas rendah atau shaley sands sampai batuan karbonat. Ini disebabkan oleh pori batuan yang tidak terkoneksi sehingga tidak sesuai dengan asumsi di atas [6].

Persamaan Gassmann menghubungkan modulus bulk batuan tersaturasi dengan pori batuan pada awalnya dan pori yang sudah terisi fluida (1). Bulk modulus suatu batuan isotropik didefinisikan sebagai perbandingan tegangan hidroststis terhadap regangan volumetrik. Perhitungan modulus bulk dapat dilakukan dengan pengukuran kecepatan di lab dan data log dengan rumus sbb:

$K_{\text {sat }}=\rho_{B}\left(V p^{2}-\frac{4}{3} V s^{2}\right)$

Dimana $\rho_{B}$ merupakan densits batuan, Vp merupakan kecepatan gelombang $\mathrm{P}$ dan $\mathrm{Vs}$ merupakan kecepatan gelombang $\mathrm{S}$.

Modulus geser merupakan perbandingan antara tegangan dengan regangan. Perhitungan modulus geser dapat menggunakan persamaan sbb:

$\mu=\rho_{B} V s^{2}$

Dimana $\mu$ merupakan modulus geser. Selain itu ada persamaan lain yang penting dalamproses substitusi fluida yaitu hubungan antara densitas fluida $\left(\rho_{f l}\right)$, porositas $(\varnothing)$, densitas matriks batuan $\left(\rho_{g}\right)$, dan densitas batuan $\left(\rho_{B}\right)$.

$\rho_{B}=\rho_{g}(1-\emptyset)+\rho_{f l} \emptyset$

Dari persamaan di atas, selanjutnya dapat dilakukan perhitungan porositas.

Sebelum memulai substitusi menggunakan persamaan, ada beberapa hal yang harus diketahui terlebih dahulu:

1. Porositas batuan $(\varnothing)$

Porositas didapatkan melalui data core atau analisis wireline data log dengan menggunakan Persamaan 4.

2. Properti fluida $\left(\mathrm{K}_{\mathrm{fl}}, \rho_{\mathrm{fl}}\right)$ 
Dalam pelaksanaan substitusi fluida, ada tiga pendekatan yang digunakan untuk menentukan modulus bulk dan densitas (fluida awal yang mengisi pori) yang belum disubstitusi maupun fluida baru yang akan dimodelkan:

a) Properti fluida diukur langsung (pada temperatur dan tekanan reservoir)

b) Properti fluida dihitung menggunakan persamaan [2] dan [5]

c) Properti fluida dihitung menggunakan kalkulator empiris (contoh, [1]).

Pada umumnya perbedaan antara modulus bulk dan densitas batuan dengan fluida awal tidak akan berbeda jauh dengan yang sudah disubstitusi, kecuali fluida memiliki rasio gas-oil (GOR) yang tinggi. Pengisi pori biasanya terdiri dari dua fluida atau lebih sehingga setiap fluida dihitung satu satu kemudian akan digabungkan berdasarkan hukum fisika. Persamaan Gassman berasumsi bahwa setiap pori batuan terkoneksi dan tekanan dalam pori sama. Dengan demikian, asumsi bahwa fluida homogen terdistribusi ke seluruh ruang pori sehingga perhitungan modulus bulk untuk fluida campuran dapat dihitung dengan isostress atau Reuss

$K_{f l}=\left[\sum_{i=1}^{n} \frac{s_{i}}{K_{i}}\right]^{-1}$

Dimana $K_{\text {fl }}$ merupakan modulus bulk dari fluida campuran dan Ki merupakan modulus bulk masing-masing fluida dan Si merupakan saturasi masing- masing jenis fluida. Densitas fluida dapat dihitung dengan persamaan berikut: $\rho_{f l}=\sum_{i=1}^{n} S_{i} \rho_{i}$

Dimana Si merupakan saturasi masing-masing jenis fluida dan pi merupakan densitas masing-masing fluida.

3. Modulus bulk matriks mineral $\left(\mathrm{K}_{\mathrm{o}}\right)$

Informasi komposisi batuan harus ada sebelum menghitung modulus bulk matriks mineral, Ko. Jika data core tidak ada, dapat menggunakan log yaitu dengan analis is volume clay (Vclay) dan berasumsi mineral terdiri dari quartz dan clay (Gambar 2.5) Perhitungan modulus bulk matriks yang terdiri dari dua mineral dapat menggunakan persamaan:

$K_{\text {Reuss }}=\left[\frac{F 1}{K 1}+\frac{F 2}{K 2}\right]^{-1}$

$K_{\text {Voigt }}=\left[F_{1} K_{1}+F_{2} K_{2}\right]$

$K_{\text {vrh }}=\frac{1}{2}\left[K_{\text {Voigt }}+K_{\text {Reuss }}\right]$

Dimana $F_{1}$ dan $F_{2}$ adalah fraksi volumetrik dari dua komponen matriks, $\mathrm{K}_{1}$ dan $\mathrm{K}_{2}$ adalah modulus bulk dari dua komponen matriks.

4. Modulus bulk kerangka batuan $\left(\mathrm{K}^{*}\right)$

Dalam aplikasi persamaan Gassmann dibutuhkan modulus bulk kerangka batuan (tanpa fluida pengisi atau $d r y$ ), $\mathrm{K}^{*}$. Nilai $\mathrm{K}^{*}$ akan konstan selama proses substitusi fluida bersamaan dengan nilai $\mu$ (modulus geser). Berikut merupakan Persamaan 2.1 yang digunakan untuk menghitung $\mathrm{K}^{*}$.

$K^{*}=\frac{K s a t\left(\frac{\phi K o}{K f l}+1-\phi\right)-K o}{\frac{\phi K o}{K f l}+\frac{K s a t}{K o}-1-\phi}$
Perlu diperhatikan, Kfl pada persamaan di atas merupakan fluida awal yang mengisi pori.

Setelah empat komponen di atas diketahui (porositas, Ko, K* dan $\mu$ ) selanjutnya dapat dilakukan perhitungan modulus bulk tersaturasi (Ksat) oleh fluida yang diinginkan. Setelah itu, dilakukan perhitungan densitas batuan yang baru (fluida yang sudah disubstitusi). Selanjutnya, setelah mendapatkan densitas batuan yang baru hasil substitusi fluida dapat dilakukan perhitungan kecepatan gelombang $\mathrm{P}, \mathrm{Vp}$ berdasarkan persamaan 2 .

$V p=\sqrt{\frac{K_{s a t}+\frac{4}{3} \mu_{s a t}}{\rho_{\text {sat }}}}$

Setelah didapatkan densitas bulk yang baru, dapat dihitung kecepatan geser, Vs

$V s=\sqrt{\frac{\mu_{s a t}}{\rho_{s a t}}}$

\section{METODOLOGI}

\section{A. Pemodelan Substitusi Fluida}

Tahap ini bertujuan untuk mengganti fluida awal (in-situ) menjadi fluida lain (air, minyak dan gas). Hasil dari pemodelan substitusi fluida ini adalah log densitas, Vp dan Vs yang baru. Langkah- langkah pemodelan substitusi fluida (Gambar 1) adalah sbb:

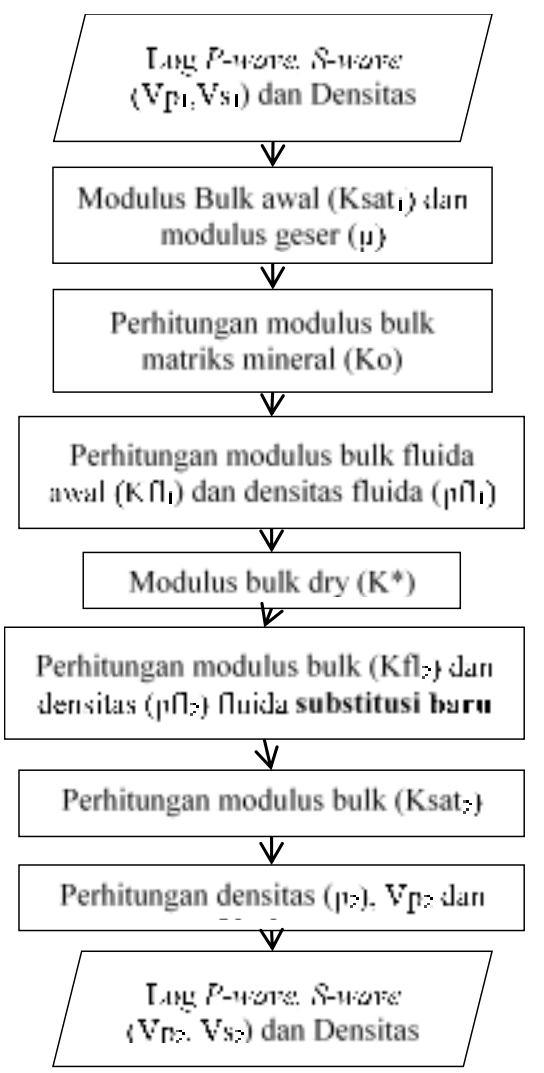

Gambar 1 Langkah kerja pemodelan substitusi fluida 


\section{HASIL DAN PEMBAHASAN}

\section{A. Analisis Pemodelan Substitusi Fluida}

Grafik hubungan antara Vp, Vs dan densitas terhadap perubahan saturasi fluida (Gambar 2, 3 dan 4) di kedalaman $1323.28 \mathrm{~m}$ dengan variasi perubahan saturasi air 0\%-100\%.

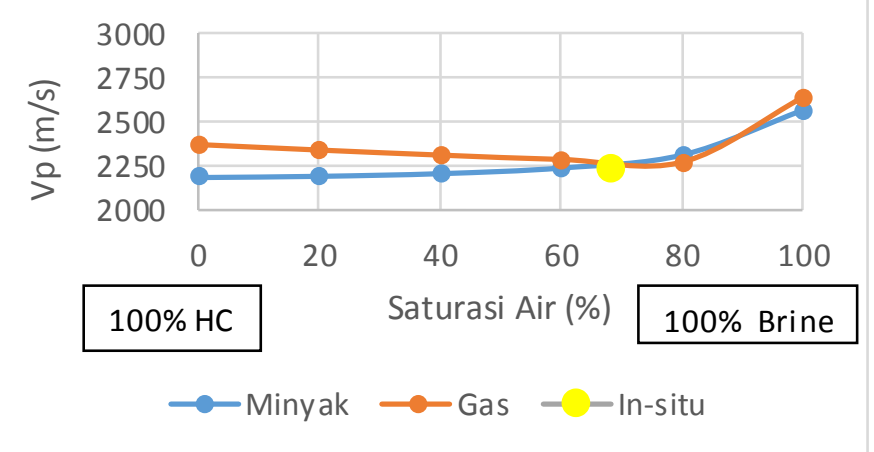

Gambar 2. Grafik Vp terhadap Saturasi air

Kecepatan gelombang P (Vp) pada batuan terisi fluida gas lebih besar dibandingkan fluida minyak. Ini merupakan kasus yang jarang yang biasa terjadi pada gas sand. Ini Terjadi akibat penurunan densitas batuan yang drastis dan kenaikan modulus bulk saturasi ketika terisi gas (11). Bentuk grafik Vp terhadap saturasi berbentuk polynomial sedangkan grafik Vs berbentuk linier (Gambar 3). Pada kasus gas, ketika saturasi air dinaikkan 0-80\% kecepatan gelombang $\mathrm{P}$ menurun dan naik ketika saturasi air $80-100 \%$. Berbeda kasus minyak, kenaikan saturasi air $0-80 \%$ berdampak pada kenaikan kecepatan gelombang $\mathrm{P}$ secara perlahan dan kenaikan secara signifikan pada saturasiair $80-100 \%$ (Gambar 6).

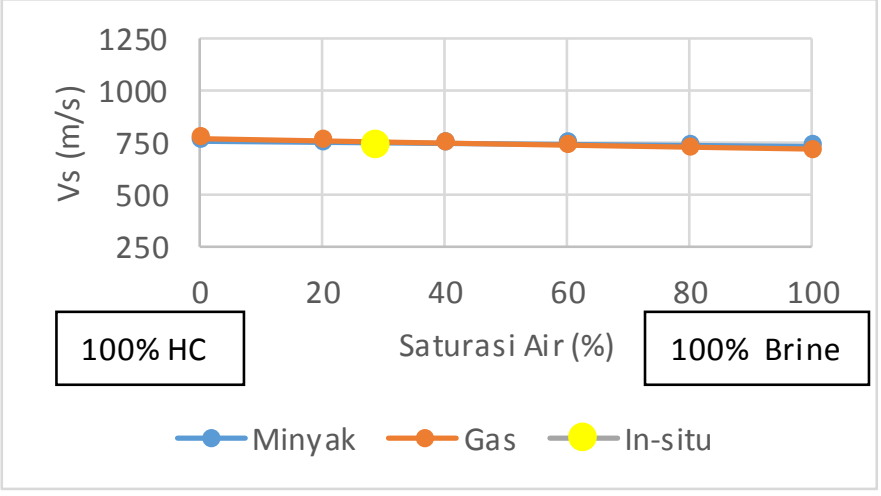

Gambar 3. Grafik Vs terhadap Saturasi Air

Perubahan kecepatan gelombang $\mathrm{S}$ tidak terlalu signifikan jika dibandingkan dengan perubahan gelombang $\mathrm{P}$ akibat saturasi air. Gambar 3 berbentuk linier dengan hubungan kecepatan berbanding terbalik terhadap kenaikan saturasi air. Kecepatan gelombang S pada fluida gas saat saturasi air 0\% lebih besar daripada fluida minyak. Ini disebabkan oleh pengaruh densitas gas dan modulus geser. Modulus geser batuan tidak dipengaruhi oleh saturasi fluida sehingga modulus batuan tersaturasi ( $\mu$ sat) sama dengan modulus batuan kerangka/ dry $\left(\mu^{*}\right)$. Fluida tidak memiliki modulus geser sehingga nilainya 0 . Ketika di substitusi dengan gas akan turun drastis dan menyebabkan nilai kecepatan gelombang $\mathrm{S}$ meningkat.

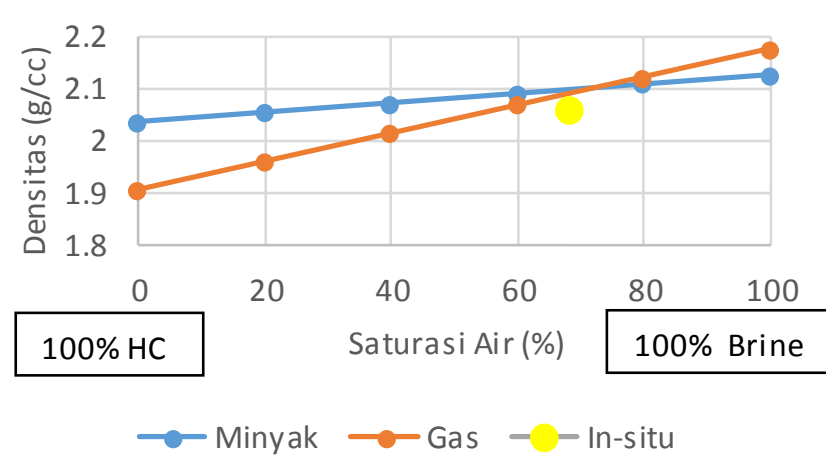

Gambar 4. Grafik densitas batuan tersaturasi terhadap saturasi Air

Densitas batuan terisi fluida gas menunjukkan perubahan yang lebih besar dibandingkan fluida minyak, ditandai dengan kemiringan grafik (Gambar 4). Densitas batuan terisi gas lebih kecil dibandingkan minyak pada keadaan saturasi air $0 \%$. Perubahan densitas berbanding lurus dengan kenaikan saturasi air.

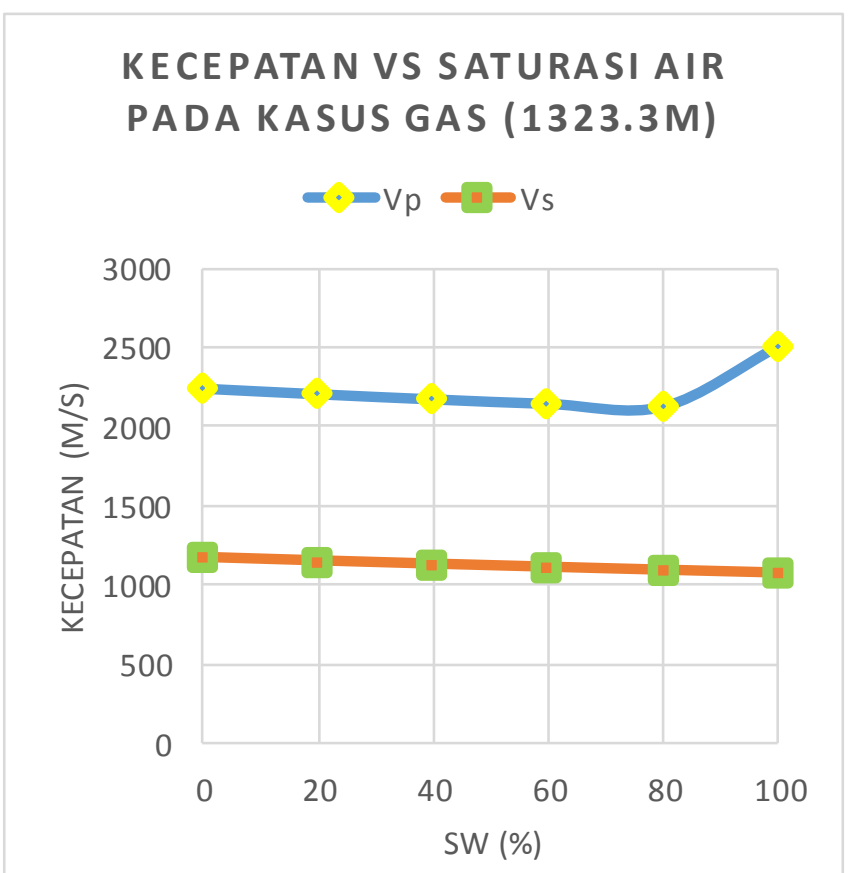

Gambar 5. Hubungan kecepatan dengan saturasi air pada kasus gas di kedalaman $1323.3 \mathrm{~m}$ 


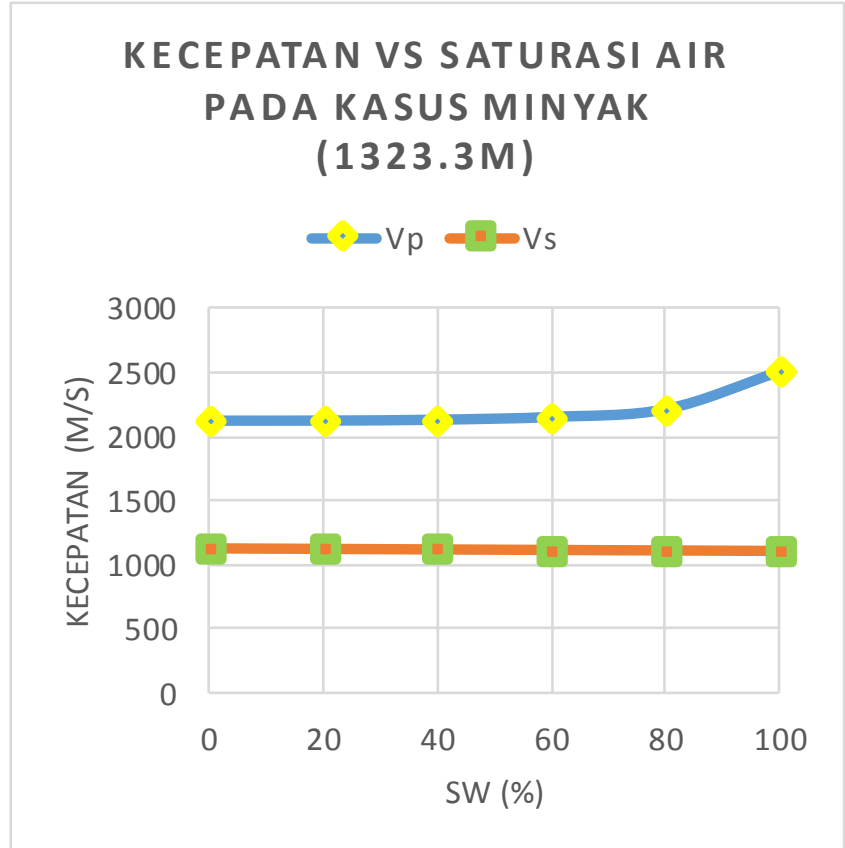

Gambar 6. Hubungan kecepatan dengan saturasi air pada kasus minyak di kedalaman $1323.3 \mathrm{~m}$

Kehadiran gas dan minyak pada batuan sangat berpengaruh terhadap kecepatan gelombang $\mathrm{P}$ (Gambar 5 dan 6). Bentuk kurva kecepatan gelombang $\mathrm{P}$ pada kasus gas dan minyak terhadap bertambahnya saturasi air berbeda. Perhitungan kecepatan gelombang $\mathrm{P}$ dan $\mathrm{S}$ dilakukan pada kedalaman 1323m dengan Porositas: 31.99\%, Kmatrix: 40Gpa, Kw= 2.38 Gpa , Kgas: 0.0185 Gpa, Koil: 0.0356 Gpa.

Bentuk kurva gelombang $\mathrm{P}$ pada kasus gas cenderung menurun seiring bertambahnya saturasi air pada $0 \%-60 \%$ kemudian pada saturasi air $60-80 \%$ mulai naik dan naik secara drastis pada saturasi $80 \%-100 \%$. Bentuk kurva gelombang $\mathrm{P}$ pada kasus minyak cenderung naik perlahan saat saturasi air 0\%-60\% kemudian naik drastis pada saturasi air 80\%-100\%. Sehingga bentuk kuva yang dihasilkan berbeda.

\section{KESIMPULAN/RINGKASAN}

Berdasarkan penelitian yang telah dilakukan dapat diambil kesimpulan bahwa:

1. Perubahan properti batuan akibat fluida pengisi pori berpengaruh terhadap kecepatan gelombang $\mathrm{P}$ dan densitas (impedans batuan)

2. Kecepatan gelombang S (Vs) ketika terisi gas akan lebih besar dibandingkan air dan minyak.

3. Kecepatan gelombang $\mathrm{P}(\mathrm{Vp})$ naik ketika terisi fluida air dan gas dan turun ketika terisi minyak.

4. Vp batuan terisi gas lebih besar dibandingkan dengan minyak.Hal ini terjadi pada kasus reservoir gas sand.

\section{UCAPAN TERIMA KASIH}

Penulis mengucapkan terima kasih kepada dosen- dosen pembimbing Dr. Amien Widodo dan Firman Syaifuddin atas ide penulisan dan pengarahannya selama proses penelitian hingga penulisan. Penulis juga ingin berterimakasih kepada orangtua dan rekan- rekan penulis yang telah memberi saran dan dukungan selama ini.

\section{DAFTAR PUSTAKA}

[1] Mariam, Yoese., 2009, Fluid Replacement Model (FRM) Analysis of Telisa Sand Reservoir: YM Field, South Sumatra Basin, Jakarta: Universitas Indonesia

[2] Gassmann, F., 1951, Uber die Elastizit “ at Por “ oser Medien: Vier. Der Natur. Gesellschaft in Z" urich, 96, 1-23.D. P. Arnold, "Review of superconducting radio-frequency cavities," submitted for publication.

[3] Smith, T. M., Sondergeld, C. H., \& Rai, C. S. (2003). Gassmann fluid substitution: A Tutorial. Geophysics, 68, 430-440.

[4] Danesh, A., 1998, PVT and phase behaviour of petroleumreservoirfluids: ElsevierI. S. Jacobs and C. P. Bean, "Fine particles, thin films and exchange anisotropy," in Magnetism, vol. III, G. T. Rado and H. Suhl, Eds. New York: Academic, 1963, pp. 271-350.

[5] McCain, W. D., 1990, The Properties of petroleum fluids: PennWell Books

[6] Batzle, M., and Wang, Z., 1992, Seismic properties of pore fluids: Geophysics, 57, 1396-1408.G. Eason, B. Noble, and I. N. Sneddon, “On certain integrals of Lipschitz-Hankel type involving products of Bessel functions," Phil. Trans. Roy. Soc. London, vol. A247, pp.529-551,Apr. 1955 . 